\title{
Nanoindentation and the micromechanics of Van Gogh oil paints
}

\author{
Johanna Salvant ${ }^{1}$, Etienne Barthel $^{2}$ and Michel Menu ${ }^{1}$ \\ ${ }^{1}$ Laboratoire du Centre de Recherche et de Restauration des Musées de France (C2RMF), CNRS UMR 171, \\ Palais du Louvre, 14, Quai François Mitterrand, Paris F-75001, France
}

${ }^{2}$ Laboratoire CNRS/Saint-Gobain "Surface du Verre et Interfaces", UMR 125,

39, Quai Lucien Lefranc, BP 135, Aubervilliers Cedex F-93303, France

johanna.salvant@culture.gouv.fr Phone number: 01402024 23, Fax number: 0147033246

\begin{abstract}
Understanding the mechanical properties of ancient paintings is a major issue for conservation and restoration. One strategy is to measure the mechanical properties of reconstructed paints: however the aging process is poorly known, so it is also desirable to measure mechanical properties directly on ancient paint samples. Using nanoindentation, we have characterized submillimetric samples recovered from restoration of two Van Gogh paintings and compared the results with reconstructed paint samples. We demonstrate that the reduced modulus and hardness of historical paints can be measured at a very local scale, even differentiating between each paint layer. Our reconstructed paint samples exhibit elastic moduli comparable to literature values, but the values measured on the two $19^{\text {th }}$ century paint samples are found to be significantly larger. Similarly, the compositional dependence of the elastic modulus is consistent with literature results for our reconstructed samples while our preliminary results for ancient samples do not readily fall into the same pattern. These results all point out to a significant impact of long term aging, in a manner which is difficult to predict in our present state of understanding. They demonstrate that nanoindentation is a very adequate tool to improve our knowledge of art paint mechanics and aging.
\end{abstract}

\section{Introduction}

In the field of conservation and restoration, a significant concern is to master the mechanical response of paintings in order to reduce mechanical damage and even correct deformation. However an oil painting is a system of great complexity: it consists of an organic support (canvas, wood) on which a thick coating has been applied. This coating typically comprises several layers, such as size, ground, colored oil paint and varnish, while the colored layer itself is often a multilayer. Understanding the mechanical behavior of such oil paintings is a daunting task. Here we focus our study on the paint multilayer itself. In the life of a painting, a primary source of stress is the tensile residual stress resulting from paint cross-linking and drying [1,2] while additional stresses arise from variation of environmental factors such as relative humidity or temperature [3-7]. Stresses also result from the deformation of the support, whether deliberately applied during restoration processes (restretching, lining) or accidentally (handling). Although mechanical stresses may result in undesirable macroscopic deformation of paintings, the main stress-related problem affecting oil paintings is the cracking of the paint layer [2].

Cracking naturally occurs to relieve the tensile stresses accumulated in the comparatively rigid paint layers. If you stretch a canvas, for a given deformation, the elastic energy stored in the paint layer is proportional to its Young modulus. This stored elastic energy may result in cracks. However, if the paint material exhibits non elastic behavior, such as viscoelasticity or viscoplasticity, the stored elastic energy may also be released gradually by stress relaxation, in a damage-less process. As a result, it is necessary to measure the mechanical properties of paint layers, focusing both on the instantaneous (elastic) response and on the rheology. 
Interest in the investigation of mechanical behavior of paintings has been growing since the late 1960s. Bearing in mind the complexity of the system we are dealing with, it is hardly a surprise that a great diversity of techniques has been used. In many studies, macroscopic mechanical tests have been performed on strips of reconstructed paint films. Newly-made paint was applied on supports (usually polyester films or glass plates) and left drying for a few months to a few years. Centimetric strips of free paint films were then removed from the support and characterized by tensile testing. From such studies, valuable information was gained on the influence of the type of pigments, aging of paint, temperature, relative humidity and solvents on the mechanical properties of paint films [5, $6,8-11]$. Effects of solvents and of relative humidity on paint properties were also investigated by thermomechanical measurements on small samples of reconstructed paint, providing information indirectly related to mechanical properties, such as the compressibility as a function of temperature or viscoelastic behavior [12,13]. All these results emphasize the fact that an oil paint is a slowly evolving system. Paint drying and cross-linking are indeed longtime processes and extrapolation of the results to centuries old paints is uneasy. This notion suggests that for a full understanding of the mechanics of ancient paintings [2,14], it is necessary to measure the mechanical properties not only of reconstructed paints, but also of ancient paints.

A few studies report the use of strips from ancient paintings or primed canvas as test samples to investigate the mechanical behavior of paintings [3, 15, 16]. A more general application of these methods to ancient paintings is problematic. Since one would normally refrain from lacerating a valuable historic painting into stripes for mechanical testing, it is necessary to find a method to investigate the mechanical response of paintings on a less destructive basis. It would also be desirable to test the mechanical response of paintings on a very local basis. Indeed, for an elaborate system such as a painting, the overall mechanical response depends upon the individual responses of the substrate and the many layers in a complex way. Even for the paint multilayer by itself, complex rupture processes may arise due to elastic modulus mismatch within the multilayer, with strong impact on the crack path selection [17]. Therefore, when measuring the elastic properties of oil paints, an average effective modulus measured for the whole painted canvas or even just the paint multilayer is not enough: ideally we would need to identify the elastic modulus of each single layer.

Nanoindentation is a local method of mechanical investigation which can partly fulfill these two requirements. Nanoindentation has been developed in the 1980s and rapidly became a standard tool to investigate the mechanical properties of small size structures such as thin films and coatings, grains, small second-phase precipitates or materials involved in microscale and nanoscale devices. Reduced elastic modulus and hardness are commonly derived from nanoindentation tests [18]. In this respect nanoindentation has already been widely used to study modern organic composite coatings. For example, it has been used in the field of automotive paint to characterize reduced modulus and hardness of each paint layer separately $[19,20]$. Mar resistance of automotive coatings could also be investigated by performing nanoscratch technique on the topcoat layer separately from the other layers [21, 22].

In this paper, we have applied nanoindentation to $19^{\text {th }}$ century paint fragments recovered after restoration. Submillimetric samples from two paintings by Van Gogh were embedded in resin and polished into cross sections. We demonstrate that for the relatively thick paint layers typical for Van Gogh the reduced elastic modulus, hardness and creep properties of each individual layer can be measured with reasonable confidence. We can clearly discriminate between the mechanical responses of various layers, and establish a relation between mechanical response and layer composition. Our results also show that typical values of reduced modulus obtained on these ancient materials are considerably larger than the reduced moduli measured on modern, reconstructed samples. Our results demonstrate that nanoindentation is a suitable tool for local investigation of 
historic paintings since very small fragments such as recovered from restoration can be tested. From nanoindentation of cross sections we also gain the benefit that each individual paint layer can be probed. Our results suggest that longtime aging (over periods of the order of a century) has to be taken into account for the understanding of the mechanical response of paintings.

\section{Experimental}

\subsection{Materials}

Oil paint is primarily a dispersion of pigments in a drying oil. Pigments are very fine insoluble particles with wavelength-selective absorption resulting in their ability to color materials, usually metal oxides or metal salts. Drying oil consists of glycerol triesters of fatty acids, with a high proportion of polyunsaturated fatty acids. Most common drying oils used in paints are linseed, poppy, walnut or safflower oil. As a result of the presence of both organic and mineral components, oil paint is a complex material, bearing strong similarities with technical composites made of a polymer matrix filled with particles [23, 24].

Several samples from ground and paint layers of Van Gogh paintings have been investigated. Here we report representative results from two samples. Samples VG1 (Fig. 1) and VG2 (Fig. 2) have been retrieved respectively from Portrait du Docteur Paul Gachet (La Faille number F754, June 1890, Musée d'Orsay, Paris) and La Salle de danse à Arles (F547, December 1888, Musée d'Orsay, Paris). Sample sizes (length by thickness) are $700 \mu \mathrm{m}$ by $240 \mu \mathrm{m}$ (VG1) and $370 \mu \mathrm{m}$ by $65 \mu \mathrm{m}$ (VG2) (Table 1). The samples were embedded in resin and polished, resulting in cross sections exhibiting the different layers. The cross sections have been investigated by SEM-EDX to characterize the layer thickness and the main mineral compounds present. For these two samples, Table 1 indicates the weight percent of the major chemical elements detected as a percentage of the total mineral fraction.

Sample VG1 presents two off-white ground layers (layer 1 and 2) and one blue painting layer (layer 3) (Fig. 1a). The thicknesses of the individual layers range between 40 and $140 \mu \mathrm{m}$ (Table 1). Ground layers are made of lead white $\left(2 \mathrm{PbCO}_{3} \cdot \mathrm{Pb}(\mathrm{OH})_{2}\right)$ (layer 2) or of a mixture of calcium carbonate $\left(\mathrm{CaCO}_{3}\right)$ and lead white (layer 1) (Table 1). The paint layer is a mixture of zinc white $(\mathrm{ZnO})$, cobalt blue $\left(\mathrm{CoO} \cdot \mathrm{Al}_{2} \mathrm{O}_{3}\right)$ and lead white (layer 3). Sample VG2 is a fragment of one single layer (Fig. 2). The yellow pigment is chrome yellow $\left(\mathrm{PbCrO}_{4}\right)$.

Samples from modern reconstructed oil paints were also investigated. Reconstructed lead white and zinc white oil paint have been made by grinding pigment powders in commercial purified linseed oil (Laverdure, huile de lin Catégorie A) with a glass muller on a frosted glass plate. The minimum amount of linseed oil possible for each pigment to obtain a workable paste was used to grind pigments. The respective weight of pigment powder and of linseed oil used to make $100 \mathrm{~g}$ of each paint are indicated in Table 1: lead white paint (LW) contains 91 weight percent (\% wt) of pigment and zinc white paint (ZW) $84 \mathrm{wt} \%$ of pigment, corresponding respectively to $58 \%$ and $47 \%$ volume concentration of pigments in the oil/pigment mixtures (Table 1). The paste has been applied on commercially primed canvas. After few months of drying, the reconstructed paint samples have been embedded in resin and polished. Samples LW and ZW are similar in thickness (respectively $350 \mu \mathrm{m}$ and $185 \mu \mathrm{m}$ ) to the ancient Van Gogh paint samples, but are larger in length (respectively $1200 \mu \mathrm{m}$ and $1960 \mu \mathrm{m})$.

\subsection{Characterization of the mechanical properties}

Nanoindentation testing was performed with an instrumented nanoindenter XP (MTS Nano Instruments, TN, USA), using a diamond Berkovich tip. A continuous measurement of the force, 
penetration and contact stiffness at $45 \mathrm{~Hz}$ was performed while loading at a rate of $0.05 \mathrm{~s}^{-1}$. To probe creep, the load was held constant at its maximum value for 60 seconds before unloading (Fig. 3). Reference measurements were performed on silica as standard. On each location, two to four series of 5 to 10 indents were carried out. The recorded measurements were converted into reduced elastic modulus $E^{*}=E /\left(1-v^{2}\right)$ and hardness using the Oliver and Pharr (1992) method [25]. Here $E$ is the Young modulus and $v$ the Poisson ratio. The tip shape was modeled as a sphere terminated cone, following Loubet et al. (1993), with an estimated sphere radius of $20 \mathrm{~nm}$ [26]. Note that the exact value of the tip radius does not impact the following results which are taken at larger penetrations.

As far as individual positioning of the indents is concerned, position calibration of the translation stage was carried out before measurement. For such minute samples, optimum positioning is needed and due to long distance drifts, calibration of the position should be implemented close to each individual sample, and not only for the positioning stage as a whole. After the measurements, the samples were observed by optical microscopy in order to assess the precise location of the indents in the multilayers.

\section{$\underline{2.3 \text { Indentation methodology }}$}

The characteristics of the samples (at the scale of the layer) and of the materials (at the scale of the pigment) further determined our choice of indentation parameters. Figure $1 \mathrm{~b}$ shows the cross-section of sample VG1: the grain size of the pigments is typically in the range of 0.5 to $30 \mu \mathrm{m}$. As a result we are faced with two conflicting constraints: 1) the total area available is strictly limited, due to the small size of the samples and some fraction of this area should be avoided, for instance close to a large inclusion; 2) the paint layers exhibit strong heterogeneity. This material heterogeneity and the limits of the polishing of the surfaces make it impossible to measure at very low depths. In fact, typical indentation curves exhibit significant "overshoots" at low penetrations (Fig. 4), which signal a modified surface, possibly due to polishing. Beyond a few hundred nanometers, fortunately, the indentation curves usually converge to a plateau (Fig. 4). Therefore the targeted penetration depth should be as large as possible, and a minimum of $2 \mu \mathrm{m}$ seems recommended. However large penetrations result in wide indents, occupying more of the specimen area. In order to be able to pack a significant number of indents in the limited space available, we decided to relax the usual rule that indents should be spaced typically three times their width, and chose a spacing of $15 \mu \mathrm{m}$ for our 2 $\mu \mathrm{m}$ deep indents. We therefore expect some degree of overlap between the deformation fields, which may affect the accuracy of our results in a manner which is difficult to quantify, but also we expect this effect to be limited with regard to the error incurred due to heterogeneity of the samples. Indeed no significant deviation was observed when using reduced spacings for the reconstructed samples.

\section{Results and discussion}

\subsection{Results: reproducibility, resolution and distribution}

After identification of each indent by optical microscopy (Fig. 2), the values of reduced modulus and hardness obtained for those indents which were found to lie well inside a given layer were used to compute the average mechanical response of each layer (Table 2). Indents found to lie on or within one indent width from a layer boundary have been discarded. We notice that a significant mechanical contrast between the various samples is observed. For the ancient samples investigated in this study, the average reduced moduli range between 4.0 and $13.6 \mathrm{GPa}$, depending on the nature of the layer investigated. The hardness is comparatively low with mean values ranging between 0.1 and $0.44 \mathrm{GPa}$. Despite the heterogeneity of the layers, the reproducibility of the results appears satisfactory in view of the computed standard deviations (standard deviation for the reduced modulus: 0.6 - 1.6 GPa; standard deviation for the hardness: 0.03 - $0.09 \mathrm{GPa}$ ). We also observe that strong differences in reduced modulus between different layers can be identified with confidence: in 
sample VG1, the reduced moduli of the first two layers (layer 1 and 2) are around 12-13 GPa, while the reduced modulus of layer 3 is half lower, around $6 \mathrm{GPa}$. In addition, a sharp contrast is observed between the reconstructed paint samples and the 120 years old samples from Van Gogh paintings. The reduced moduli of the former range between 0.5 and $2.1 \mathrm{GPa}$, to be compared to the 4.0 to 13.6 GPa observed in the latter.

Beyond the direct measurement of reduced modulus and hardness, some information can be gathered on time-dependent mechanical processes. Indeed, creep has been observed on all the paint samples tested. On figure 5, the displacement into the surface is plotted against time during the hold period for the reference (silica) sample, for layer 2 of sample VG1 and for reconstructed sample LW. While silica exhibits negligible creep as expected, the modern sample is characterized by a significant time dependent response. It is interesting to note that the ancient samples also experience creep of the same order of magnitude. We have found that such a time dependent response is typical of all the ancient paint layers studied here. These results demonstrate that despite their significantly larger reduced modulus, these paints still flow, even after drying for over a century.

\section{$\underline{3.2 \text { Discussion }}$}

The differences in reduced modulus and hardness observed for the various samples from ancient or reconstituted paints result from a complex combination of factors, pertaining to the matrix, the pigment and to their interaction. However two major parameters can be stated. On the one hand, the filler content will obviously affect the final mechanical properties after drying. Unfortunately the filler content is often difficult to assess especially for small samples of ancient paint. Also we may expect that during paint formulation, the pigment content has been chosen based on both optical and rheological requirements for the application of the paint layer, and not on the basis of final mechanical properties. Indeed we found that the useable ranges are rather narrow in practice, and limited variations of pigment content should be expected. On the other hand, the mechanical properties of the composite will also depend upon the "dried" cross-linked matrix. This oil paint "drying" process is the result of autoxidation and subsequent polymerization of the unsaturated fatty acids groups in the triglycerides [27]. The process of autoxidation, the insertion of dioxygen within the unsaturated fatty acids, results in the formation of reactive hydroperoxydes, which can be involved in crosslinking reactions. This sensitive process can obviously be affected by a number of factors, and this is likely the most sensitive parameter to be considered in the understanding of the mechanical properties of paints.

The results we obtained for reconstituted samples are comparable in magnitude to literature results obtained by tensile measurements on free paint films. By both techniques, moduli are found to range between 0.5 and $2 \mathrm{GPa}$. We also note that our reconstructed zinc white sample $\mathrm{ZW}$ exhibits significantly higher reduced modulus than reconstructed lead white LW ( 2.1 vs. $0.5 \mathrm{Gpa}$ ). Zinc white paint is usually described as a very brittle paint compared to paints based on other pigments. Indeed, Mecklenburg et al (2005) previously reported that zinc white oil paint is a stiff and brittle paint, with a very high Young modulus (1.7 GPa), significantly higher than lead white paint (Young modulus of $0.3 \mathrm{GPa}$ ) [5]. Our nanoindentation results are therefore fully consistent with the tensile test results.

Mecklenburg et al (2005) and Fuesers and Zumbühl (2008) studied the impact of up to 14 year aging on the mechanical properties of free paint films [5, 11]. No saturation of the mechanical response is observed over this long aging time so that extrapolation to centuries is difficult. Direct comparison with the mechanical response of the present ancient samples is made difficult because the pigment contents were not specified in the earlier studies. It is unlikely however that the significant difference (for example from ca 0.5 GPa to ca 11-14 GPa for lead white) could be due to the difference in pigment content alone, all the more so as we were careful to investigate the highest 
possible pigment content in our own reconstituted samples. We conclude that aging over 120 years does impact the mechanical response significantly compared to a mere 15 year aging, and that this aging is primarily driven by the oil matrix cross-linking.

Within the limited range of ancient paint samples investigated here by nanoindentation, we can provide a few suggestions as to the impact of the nature of the pigments. From sample VG1, it appears that the layers which exhibit a higher reduced modulus (between 11 and $14 \mathrm{GPa}$ ) are characterized by a high relative content of lead white (around 55 and 90 weight percent of lead (sample VG1, respectively layers 1 and 2)). Mecklenburg et al (2005) indicate that the presence of zinc white, even as secondary pigment in lead white paint or in light color paint, often induces brittleness of the oil paint film within as early as three years [5]. It is therefore especially surprising that layer 3 of VG1, which contains a majority of zinc white and cobalt blue, together with some lead white ( $\mathrm{Zn} 33 \%$ atomic, $\mathrm{Al} \mathrm{37 \%}$ atomic and $\mathrm{Pb} 13 \%$ atomic of the mineral fraction) exhibits a quite low reduced modulus $(6.1 \mathrm{GPa})$ in comparison to the layers from which zinc white is absent. In this respect, we note that the chrome yellow paint layer (VG2) also exhibits a low reduced modulus (4 $\mathrm{GPa}$ ). Again, since the relative organic content is unknown for the ancient paint fragments, it impossible to draw definite conclusions but we can at least say that in terms of composition, the results we obtained on the ancient samples are counter-intuitive. Once again, we are led to conclude that the aging process, which operates over very long periods of time, is difficult to infer directly from the results obtained on reconstituted paint samples and that more measurements on ancient paint samples are needed.

Finally we would like to emphasize the significance of the creep behavior evidenced in figure 3. Creep, which is further penetration at fixed load due to rearrangement in the material, implies the possibility of stress relaxation. If the material is subjected to constant deformation, the same material rearrangement process will result in the decay of the tensile stresses. In practice, in the context of paintings, stress relaxation is therefore a process by which cracking may be avoided after intentional or accidental support deformation. It is therefore useful to understand not only the instantaneous response such as elastic modulus, but also the time dependence of the mechanical response as a function of material parameters such as -- especially -- pigment content and the aging of the material. In its own limited way, nanoindentation is also capable of providing such information.

\section{Conclusions}

In conclusion, the potential of nanoindentation as a local method to characterize the mechanical properties of paint layers has been explored. Small sub-millimeter samples can be used, which opens up for the investigation of material retrieved from valuable ancient paintings. We find that our nanoindentation results for reconstituted samples are fully consistent with literature data obtained by tensile testing. However, our preliminary results on ancient paintings evidence significantly larger reduced moduli, which points out to the impact of long time aging. Nanoindentation also enables the investigation of reduced modulus and hardness layer by layer within a paint multilayer, which provides for a better understanding of the micromechanics of the system. In our example, we find that the strong contrast between the reduced modulus of the two lead white based layers and the predominantly zinc white layer from sample VG1 is at variance with accepted ideas on the respective impacts of lead and zinc whites. These results further point out to the difficulty of extrapolating aging behaviors to the timescales relevant for ancient paintings. Significant creep has also been evidenced for these ancient samples, which suggests that these materials are capable of stress relaxation, a useful insight for restoration purposes.

Micrometric samples are often taken off paintings for conservation treatments and/or research 
(structure of paint layers, chemical composition, soap formation, etc). In this context, nanoindentation could give the opportunity to investigate the influence of various parameters on a large range of naturally aged samples for better general understanding of the mechanical behavior of oil paints and their aging over historic periods of time. More generally we can imagine a number of applications for this method. The rather complete information provided by nanoindentation could also give the opportunity to identify materials similar in reduced modulus and hardness to the original paint material if paint loss should be restored. It could also help to define the required properties of consolidating adhesives to be used for restoration. Potentially, before performing conservation treatment with solvents, its impact on the mechanics of the paint could be tested directly on a submillimetric sample with nanoindentation.

\section{Acknowledgements}

We thank Y. Adda for the original suggestion, P. Lehuédé for giving us the opportunity to work together on this project, A. Distel and J.-P. Rioux for providing us with the microsamples from Van Gogh paintings, and J. Teisseire and S. Poissonnet for some initial measurements.

\section{References}

[1] S. Keck: Studies in Conservation 14, 9 (1969)

[2] L. Pauchard, V. Lazarus, B. Abou, K. Sekimoto, G. Aitken, C. Lahanier: Reflets de la physique 3, 5 (2007)

[3] G. Hedley: Studies in Conservation 33, 133 (1988)

[4] A.A. Karpowicz: Journal of the American Institute for Conservation 29(2), 169 (1990)

[5] M. Mecklenburg, C. Tumosa, D. Erhardt: Materials Issues in Art and Archaeology VII 852, 13 (2005)

[6] M.F. Mecklenburg, L. Fuster Lopez, in Proceedings of the third international conference Colour and conservation, November 2006 (Milan, 2006)

Available on http://si-pddr.si.edu/jspui/bitstream/10088/11181/1/mci_CESMAR7p49-58.pdf

[7] M. F. Mecklenburg, in Museum Microclimates, ed. by T. Padfield, K. Borchersen, November 2007 (Copenhagen, 2007), 19-25

Available on http://www.conservationphysics.org/mm/mecklenburg/mecklenburg.pdf

[8] P.M. Whitmore, V.G. Colaluca: Studies in Conservation 40, 51 (1995)

[9] D. Erhardt, C.S. Tumosa, M.F. Mecklenburg: Studies in Conservation 50 (2), 143 (2005)

[10] C.R.T. Young, in Modern Paints Uncovered, May 2006 (Postprints Tate/ Getty/ NGA Symposium, 2006), 247-256.

Available on http://www.courtauld.ac.uk/people/young-christina/PDF\%205\%20MPU.pdf

[11] O. Fuesers, S. Zumbühl, in $9^{\text {th }}$ International Conference on NDT of Art, May 2008 (Jerusalem, 2008). Available on http://www.ndt.net/article/art2008/papers/219Fuesers.pdf

[12] G. Hedley, M. Odlyha, A. Burnstock, J. Tillinghast, C. Husband: Journal of Thermal Analysis 37, 2067 (1991) 
[13] M. Odlyha, T.Y.A Chan, O. Pages: Thermochimica Acta 263, 7 (1995)

[14] J. Boon, E. Oberthaler, in Vermeer, Die Malkunst - Spurensicherung an einem Meisterwerk: Ausstellungskatalog des Kunsthistorischen Museums Wien 2010, ed. by S. Haag, E. Oberthaler, S. Pénot (Residenz Verl., Wien, 2010), 328-335

[15] M. F. Mecklenburg: Some aspects of the mechanical behavior of fabric supported paintings, Report submitted to the Smithsonian Institution, Washington, D.C. (1982)

[16] C.R.T. Young: Optics and Lasers in Engineering Special Edition 31 (2), 163 (1999)

[17] J.W. Hutchinson, Z. Suo: Advances in Applied Mechanics 29, 63 (1992)

[18] A.C. Fischer-Cripps: Nanoindentation (Springer- Verlag New York LCC 2004)

[19] P. Bertrand-Lambotte, J. L. Loubet, C. Verpy, S. Pavan: Thin Solid Films 398-399, 306 (2001)

[20] S.V. Hainsworth, P.J. Kilgallon: Progress in Organic Coatings 62, 21 (2008)

[21] L. Lin, G.S. Blackman, R.R. Matheson: Prog. Org. Coat. 40, 85 (2000)

[22] L. Lin, G.S. Blackman, R.R. Matheson: Mater. Sci. Eng. A 317, 163 (2001)

[23] N. Chemin, L. Rozes, C. Chanéac, S. Cassaignon, E. Le Bourhis, J.-P. Jolivet, O. Spalla, E. Barthel, C. Sanchez : Chemistry of Materials 20, 4602 (2008)

[24] Wacharawichanant, S. Thongyai, A. Phutthaphan: Polymer Testing 27, 971 (2008)

[25] W.C. Oliver, G.M. Pharr: Journal of Material Research 7, 1564 (1992)

[26] J. L. Loubet, M. Bauer, A. Tonck, S. Bec, B. Gauthier-Manuel: NATO Advanced Study Institute Series E 233, 429 (1993)

[27] H. Wexler: Chemical Reviews 64 (6), 591(1964)

\section{Table and figure captions}

Table 1: Characteristics of the samples investigated (size of the sample, layer thickness and chemical composition).

Table 2: Reduced modulus and hardness (range and mean) obtained for the different samples investigated.

Figure 1: (a) Optical microscope image of sample VG1, showing the off-white ground layers (layer 1 and layer 2, applied on top of the canvas) and the blue painting layer (layer 3, applied on top of the ground layers) (b) SEM backscattering image of sample VG1 showing the three layers and their heterogeneity.

Figure 2: Optical microscope image of sample VG2 after nanoindentation measurements.

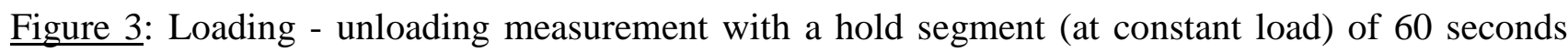
(sample VG1).

Figure 4: Reduced modulus as a function of penetration for ten measurements on sample VG2. 
Figure 5: Creep: displacement into the surface as a function of time during the hold period (constant load) in case of silica standard, sample from Van Gogh painting (VG1) and sample from modern reconstructed paint $(\mathrm{LW})$.

\section{Tables and figures}

Table 1

\begin{tabular}{|c|c|c|c|c|c|c|}
\hline $\begin{array}{l}\text { Van Gogh } \\
\text { paint samples }\end{array}$ & $\begin{array}{l}\text { Sample size : } \\
\text { largest length by } \\
\text { largest thickness } \\
(\mu \mathrm{m})\end{array}$ & $\begin{array}{l}\text { Layer(s) - color, } \\
\text { thickness }(\mu \mathrm{m})\end{array}$ & Main compound(s) & \multicolumn{3}{|c|}{$\begin{array}{l}\text { Weight percent of the main elements in the } \\
\text { mineral fraction (SEM-EDX) }\end{array}$} \\
\hline \multirow{3}{*}{ VG1 } & \multirow{3}{*}{$700 \times 240$} & Layer 1 - off white, 60 & $\begin{array}{l}\text { Calcium carbonate, } \\
\text { lead white }\end{array}$ & \multicolumn{3}{|c|}{$56 \% \mathrm{~Pb} 22 \% \mathrm{Ca}$} \\
\hline & & Layer 2 - off white, 40 & Lead white & \multicolumn{3}{|l|}{$92 \% \mathrm{~Pb}$} \\
\hline & & Layer 3 - blue, 140 & $\begin{array}{l}\text { Zinc white, } \\
\text { cobalt blue, } \\
\text { lead white }\end{array}$ & \multicolumn{3}{|c|}{$\begin{array}{l}40 \% \mathrm{~Pb} \quad 32 \% \mathrm{Zn} \\
15 \% \mathrm{Al} \quad 5 \% \mathrm{Co}\end{array}$} \\
\hline VG2 & $370 \times 65$ & Layer 1 - yellow, 65 & Chrome yellow & \multicolumn{3}{|c|}{$74 \% \mathrm{~Pb} 17 \% \mathrm{Cr}$} \\
\hline $\begin{array}{l}\text { Reconstructed } \\
\text { paint samples }\end{array}$ & $\begin{array}{l}\text { Sample size : } \\
\text { largest length by } \\
\text { largest thickness } \\
(\mu \mathrm{m})\end{array}$ & $\begin{array}{l}\text { Layer(s) - color, } \\
\text { thickness }(\mu \mathrm{m})\end{array}$ & $\begin{array}{l}\text { Pigment ground in } \\
\text { linseed oil } \\
\text { (manufacturer) }\end{array}$ & $\begin{array}{l}\text { Weight } \\
\text { percent } \\
\text { of oil }\end{array}$ & $\begin{array}{l}\text { Weight } \\
\text { percent of } \\
\text { pigment }\end{array}$ & $\begin{array}{l}\text { Volume } \\
\text { concentration of } \\
\text { pigment }(\%) \\
\text { in paint }\end{array}$ \\
\hline LW & $1200 \times 350$ & Layer 1 - white, 350 & $\begin{array}{l}\text { Lead white } \\
\text { (Natural Pigment, } \\
\text { Dutch process } \\
\text { manufacturing) }\end{array}$ & 9 & 91 & 58 \\
\hline $\mathrm{ZW}$ & $1960 \times 185$ & Layer 1 - white, 185 & $\begin{array}{l}\text { Zinc white } \\
\text { (Kremer) }\end{array}$ & 16 & 84 & 47 \\
\hline
\end{tabular}

Table 2

\begin{tabular}{|c|c|c|c|c|c|c|c|c|}
\hline \multirow{2}{*}{ Sample } & \multirow{2}{*}{ Profile } & \multicolumn{2}{|c|}{ Reduced modulus E (Gpa) } & \multicolumn{2}{c|}{ Hardness H (Gpa) } & Number of \\
& & Range & Mean & $\begin{array}{c}\text { Standard } \\
\text { deviation }\end{array}$ & Range & Mean & $\begin{array}{c}\text { Standard } \\
\text { deviation }\end{array}$ & $\begin{array}{c}\text { ther } \\
\text { layer }\end{array}$ \\
\hline VG1 & layer 1 & $11.3-17.5$ & $\mathbf{1 3 . 6}$ & 1.6 & $0.29-0.63$ & $\mathbf{0 . 4 1}$ & 0.09 & 18 \\
& layer 2 & $10.1-13.6$ & $\mathbf{1 1 . 6}$ & 1.0 & $0.34-0.64$ & $\mathbf{0 . 4 4}$ & 0.08 & 10 \\
& layer 3 & $4.6-9.0$ & $\mathbf{6 . 1}$ & 1.2 & $0.14-0.46$ & $\mathbf{0 . 2 4}$ & 0.08 & 15 \\
\hline VG2 & layer 1 & $3.0-4.7$ & $\mathbf{4 . 0}$ & 0.6 & $0.04-0.14$ & $\mathbf{0 . 1 0}$ & 0.03 & 10 \\
\hline LW & layer 1 & $0.3-1.1$ & $\mathbf{0 . 5}$ & 0.2 & $0.001-0.01$ & $\mathbf{0 . 0 0 6}$ & 0.003 & 33 \\
\hline ZW & layer 1 & $1.1-2.8$ & $\mathbf{2 . 1}$ & 0.5 & $0.02-0.08$ & $\mathbf{0 . 0 4}$ & 0.015 & 22 \\
\hline
\end{tabular}


Figure 1
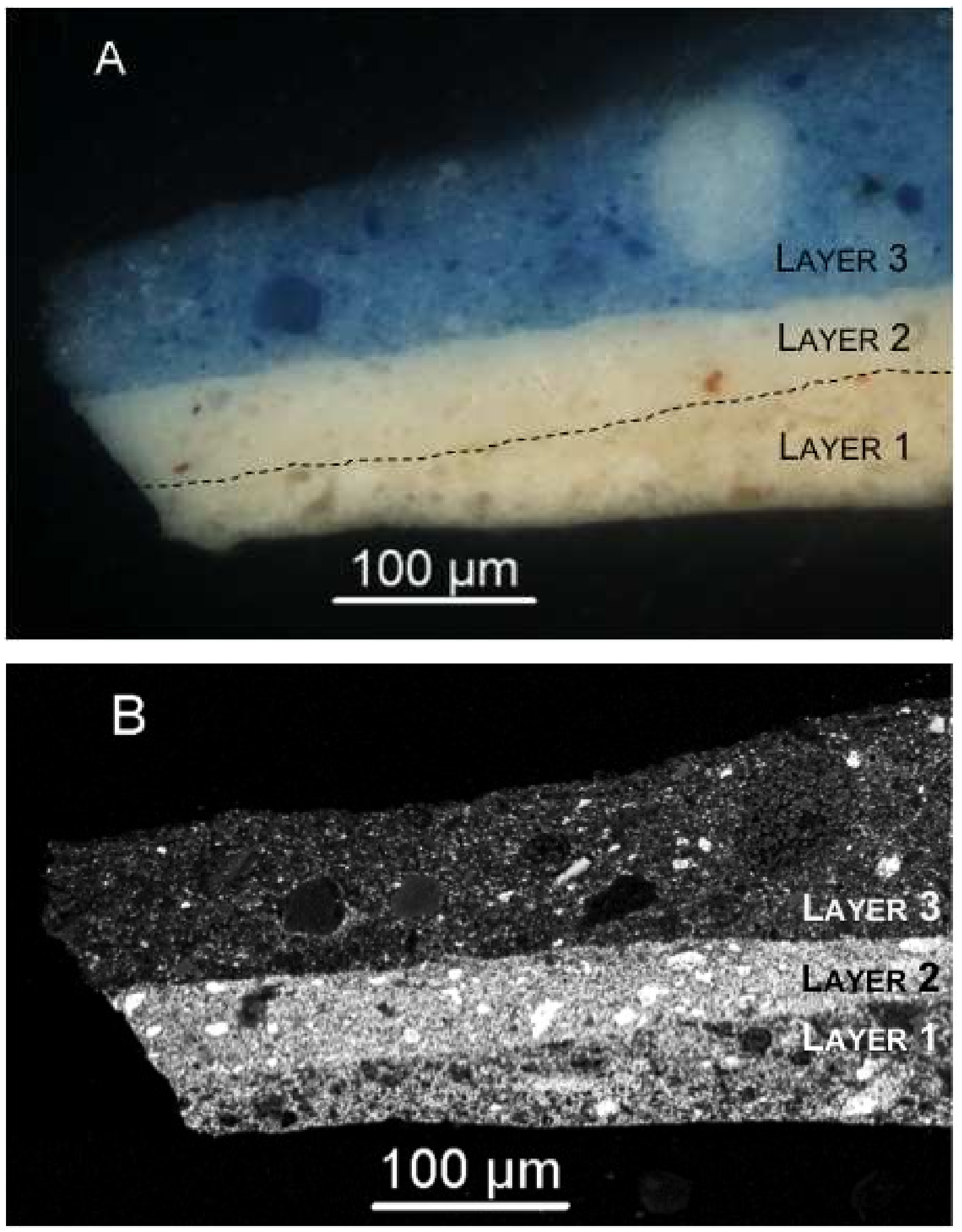
Figure 2

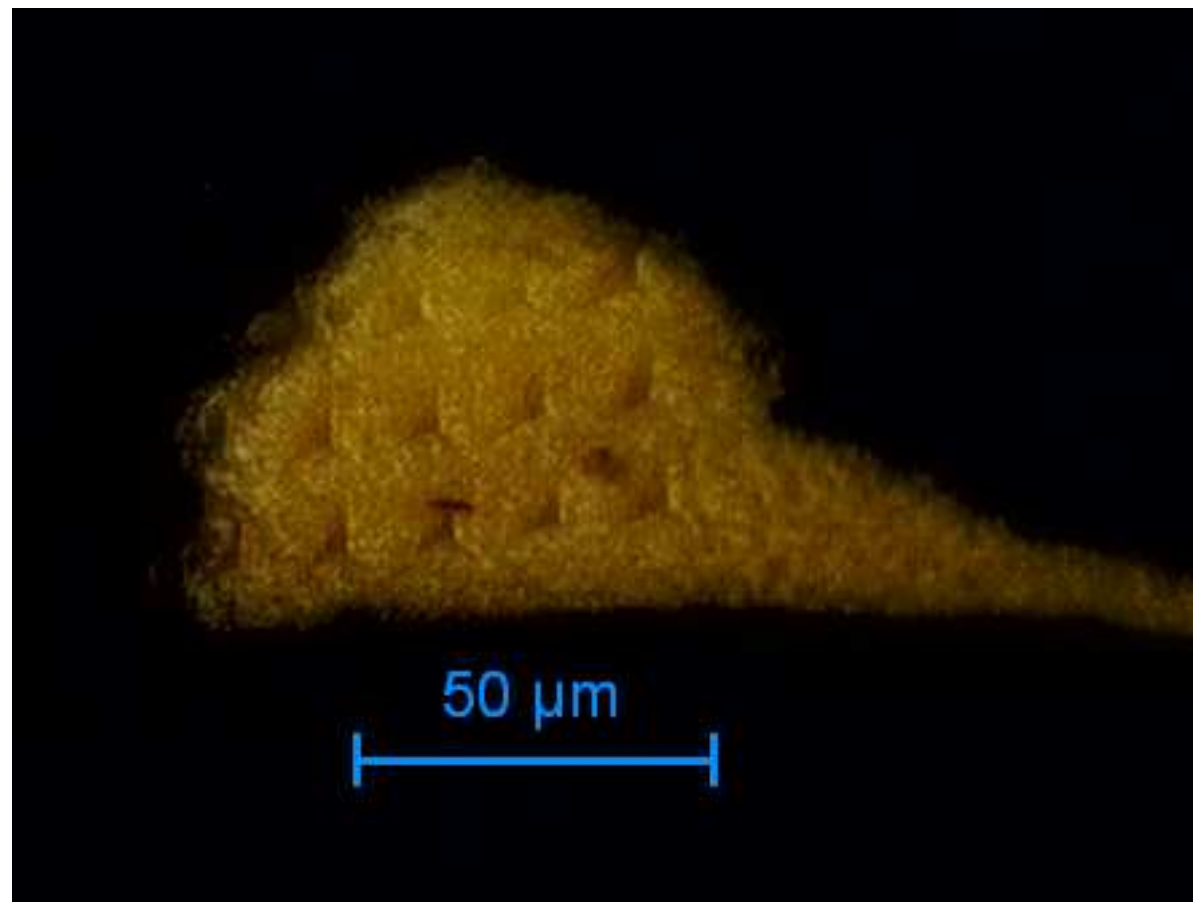

Figure 3

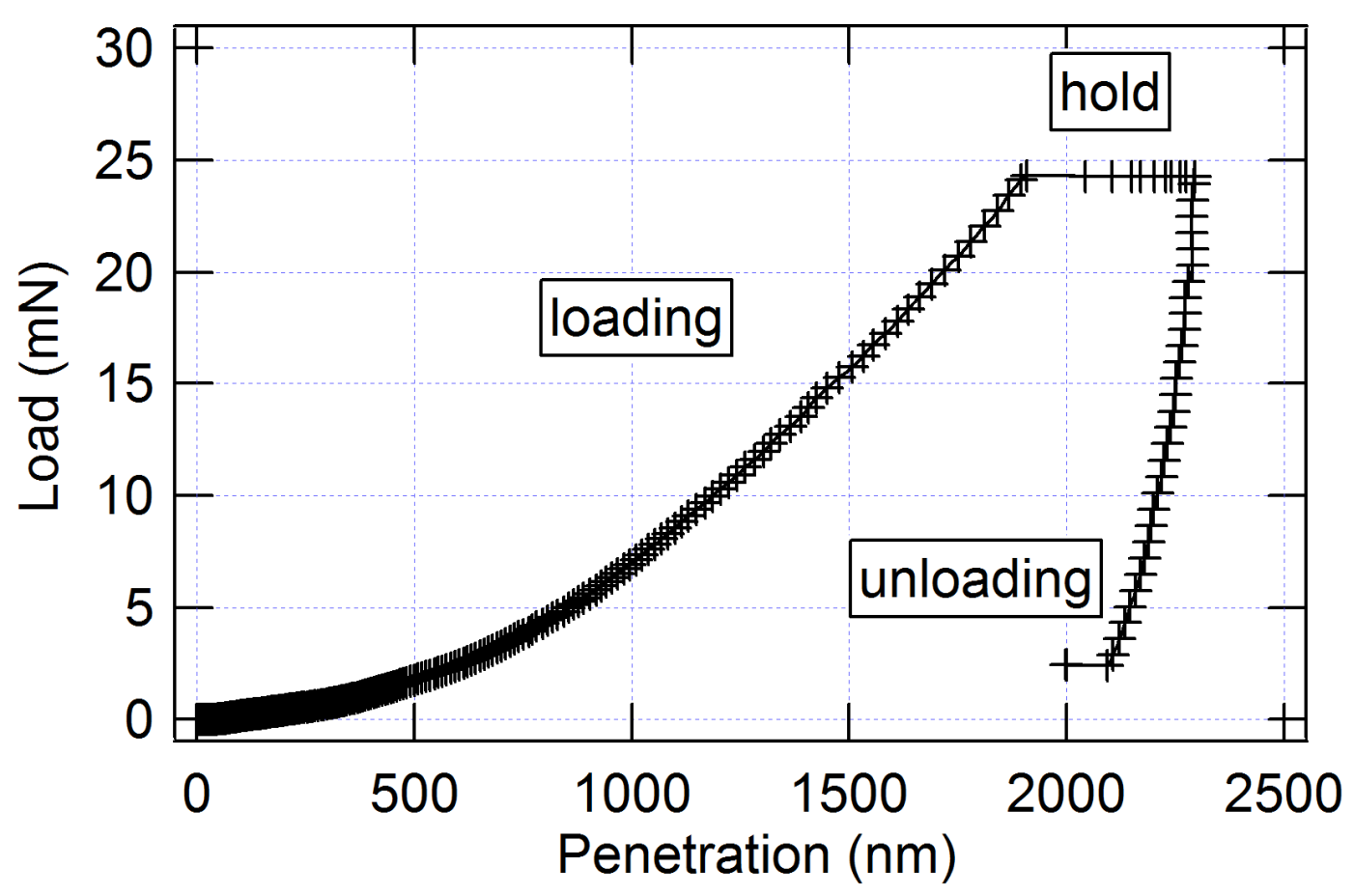


Figure 4

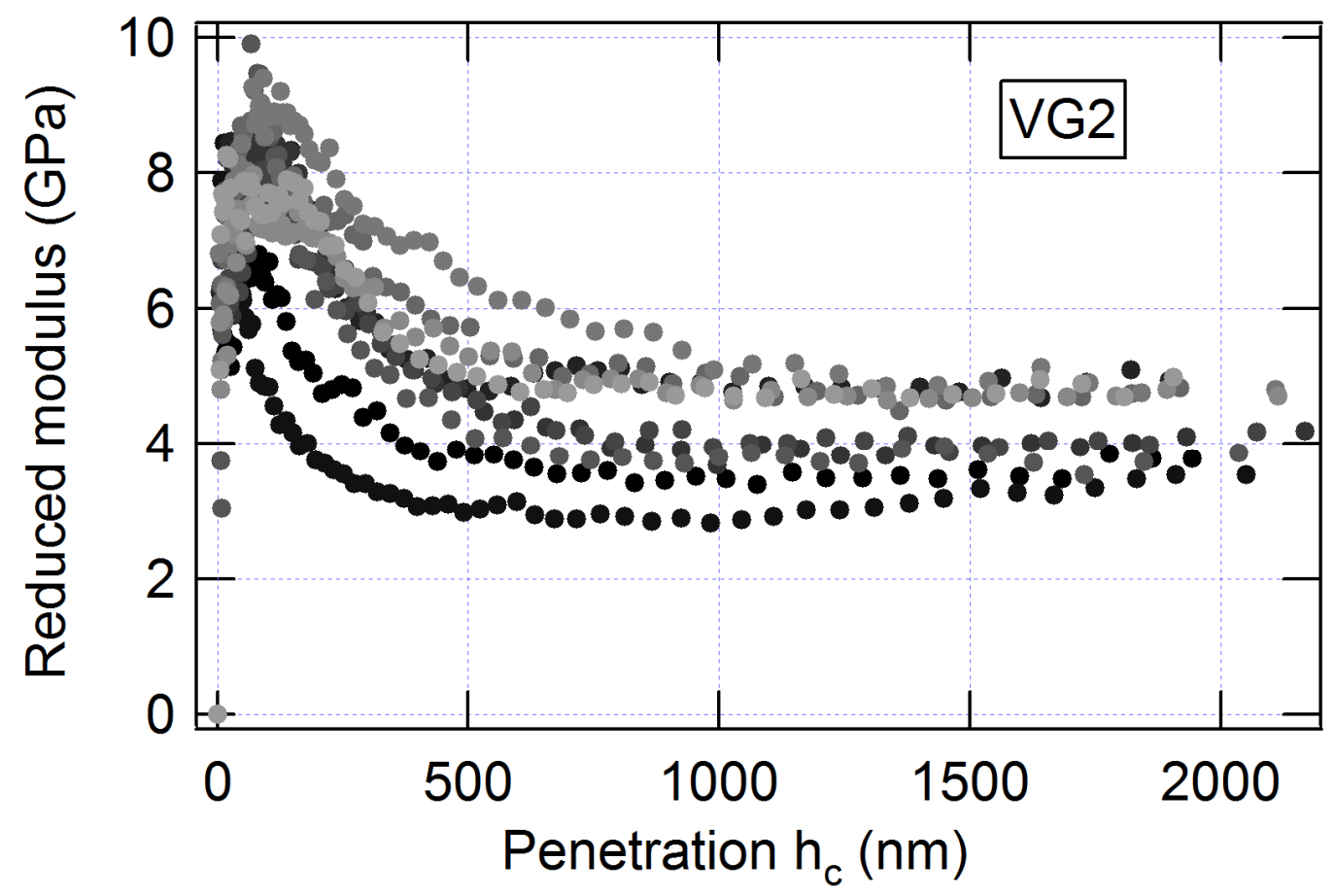

Figure 5

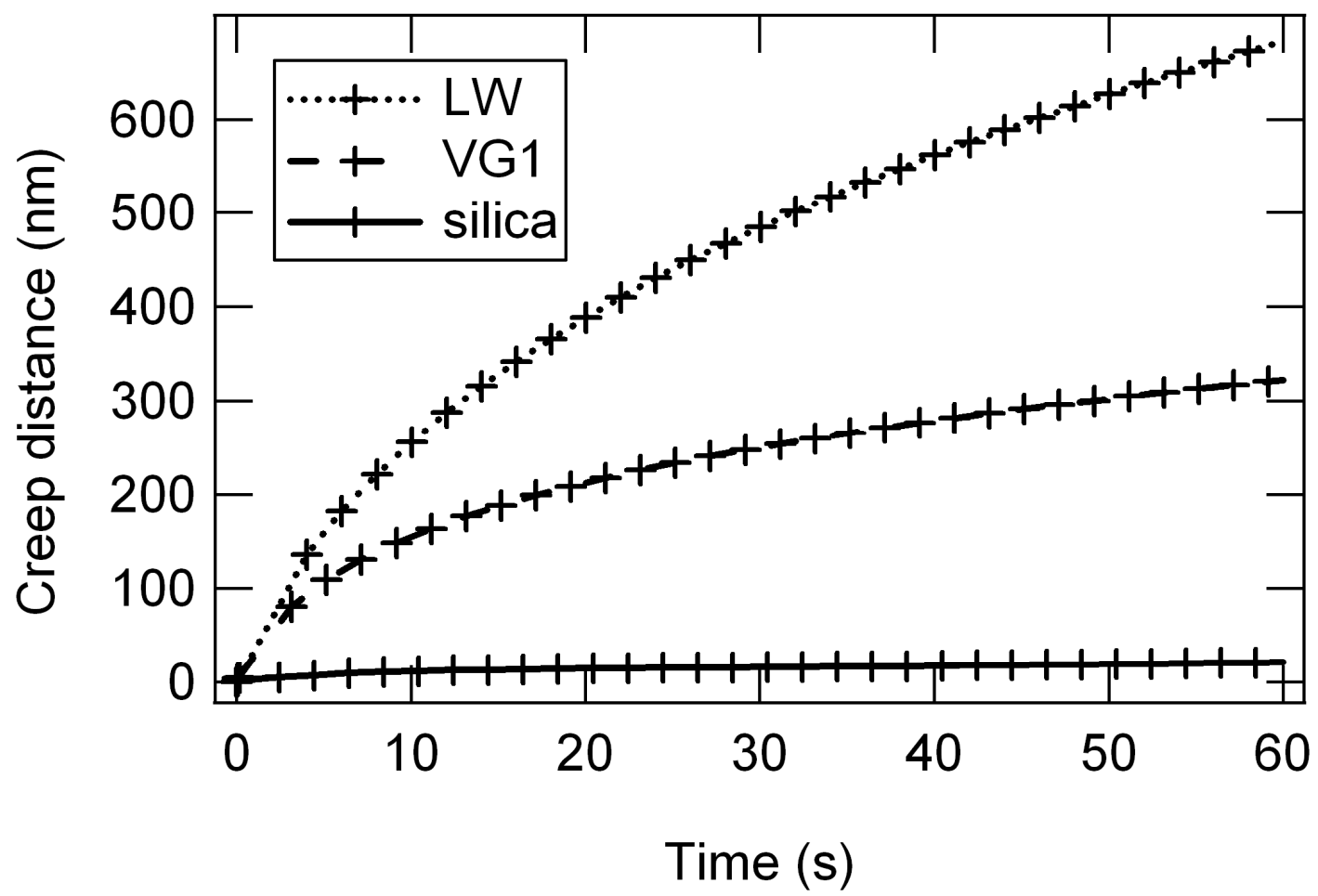

